\title{
Influência dos aspectos socioeconômicos, financeiro- orçamentários e político-eleitorais na transparência dos governos locais
}

\author{
Juliano Francisco Baldissera 1 \\ Denis Dall'Asta ${ }^{1}$ \\ Luiz Fernande Casagrande 2 \\ Abdinardo Moreira Barreto de Oliveira ${ }^{3}$ \\ 1 Universidade Estadual do Oeste do Paraná / Programa de Pós-Graduação em Contabilidade, Cascavel / PR - Brasil \\ 2 Universidade Tecnológica Federal do Paraná / Departamento de Ciências Contábeis, Pato Branco / PR - Brasil \\ 3 Universidade Tecnológica Federal do Paraná / Departamento de Administração, Pato Branco / PR - Brasil
}

Este estudo tem por objetivo analisar a influência dos aspectos socioeconômicos, financeiro-orçamentários e políticoeleitorais na transparência ativa e passiva dos governos locais brasileiros. A partir de 3.550 municípios brasileiros, realizou-se a reamostragem de 100.000 amostras e, utilizando o método de regressão linear múltipla com dados de seção transversal, obteve-se melhor robustez e confiabilidade dos dados. Os resultados indicam que em municípios maiores existe maior propensão a divulgar informações de modo ativo para diminuir os custos de agência. Uma população com renda per capita elevada exige mais informações, pois busca saber onde seus impostos são aplicados, o que exige uma sociedade mais bem-educada. Os investimentos de capital são de interesse da sociedade, por isso se espera que o nível de transparência seja maior onde houver mais gastos desse tipo. A competição eleitoral exige do gestor público uma postura mais transparente diante de seus adversários e da população para confirmar suas promessas pré-eleitorais. Palavras-chave: transparência; divulgação; teoria da escolha pública; gestão pública; municípios.

\section{Influencia de los aspectos socioeconómicos, financiero-presupuestarios y políticos-electorales en la transparencia de los gobiernos locales}

Este estudio tiene como objetivo analizar la influencia de los aspectos socioeconómicos, financiero-presupuestarios y políticos electorales en la transparencia activa y pasiva de los gobiernos locales brasileños. A partir de 3.550 municipios brasileños, se realizó el remuestreo de 100.000 muestras y, utilizando el método de regresión lineal múltiple con datos de sección transversal, fue posible obtener una mejor robustez y confiabilidad de los datos. Los resultados indican que en municipios mayores existe una mayor propensión a divulgar información de forma activa para disminuir los costos de agencia. Una población de renta per cápita elevada exige más información, pues busca saber dónde se aplican sus impuestos, lo que exige una sociedad mejor educada. Las inversiones de capital son de interés de la sociedad, por lo que se espera que el nivel de transparencia sea mayor donde haya más gastos de este tipo. La competencia electoral exige del gestor público una postura más transparente frente a sus adversarios y población para confirmar sus promesas preelectorales.

Palabras clave: transparencia; divulgación; teoría de la elección pública; gestión pública; municipios.

\section{Influence of socio-economic, financial-budgetary and political-electoral aspects on the transparency of local governments}

This study aims to analyze the influence of socioeconomic, financial-budgetary and political-electoral aspects on the active and passive transparency of Brazilian local governments. From 3,550 Brazilian municipalities, a resampling of 100,000 samples was performed using the multiple linear regression method with cross-sectional data, obtaining better data robustness and reliability. The results indicate that in larger municipalities there is a greater propensity to actively disseminate information to reduce agency costs. A population with higher per capita income and better educated tend to demand more information, seeking to know where is the taxpayers' money invested. Capital investments are important to society, so it is expected that the level of transparency will be higher where there is more spending of this kind. Electoral competition require public managers to be more transparent toward their opponents and population to confirm their pre-election promises.

Keywords: transparency; disclosure; public choice theory; public administration; local governments. 


\section{INTRODUÇÃO}

O debate sobre a transparência pública se mostra necessário para compreender as vantagens e desvantagens de seu uso e a dinâmica e complexidade desse fenômeno (Bannister \& Connolly, 2011; Etzioni, 2010; Grimmelikhuijsen \& Welch, 2012; Meijer, 2009). A transparência é um desafio para a atual e a futura reforma da administração pública e para uma governança mais moderna e mais eficiente (Piotrowski \& Van Ryzin, 2007).

A transparência pública envolve a disponibilização de informações de modo contínuo para as partes interessadas externas, sendo utilizada para melhorar a compreensão do que o governo vem realizando (Meijer, 2013; Porumbescu, 2015). Essa definição abrange 2 tipos de divulgação: a) transparência ativa, a qual é desenvolvida proativamente pela agência; b) transparência passiva, quando a entidade responde de modo reativo às demandas externas por meio de pedidos de informação (Grimmelikhuijsen \& Welch, 2012).

A transparência possibilita monitorar e avaliar o desempenho de representantes e servidores públicos. É um componente importante da boa governança e da qualidade institucional (Sol, 2013). É construída por meio de interações complexas entre diversos atores políticos e sociais, dentro do conjunto de regras formais e informais, com a disponibilidade de uma variedade de tecnologias novas e em constante evolução (Meijer, 2013).

A transparência se mostra desejável na perspectiva econômica, uma vez que aumenta a eficiência na alocação de recursos, reduzindo os problemas entre o principal e o agente (Hölmstrom, 1979), desencorajando as atividades de busca de rendas (Calderón \& Chong, 2006). Entretanto, a assimetria de informação distorce essa relação (Lane, 2006) justificada pela racionalidade limitada dos indivíduos (Oliveira \& Fontes, 2017).

O homem enquanto maximizador de utilidade (Buchanan \& Tullock, 1962), egoísta e racional (Mueller, 1976), pode explicar o comportamento dos políticos no comando da gestão pública (Buchanan \& Tullock, 1962; Mueller, 1976). Essas perspectivas teóricas podem ser utilizadas para entender a dinâmica da transparência nos governos locais brasileiros.

Os estudos têm abordado o impacto dos fatores sociais, econômicos, políticos, organizacionais e institucionais na divulgação de informações financeiras no setor público. Entretanto, os aspectos relacionados ao ciclo político ainda parecem inexplorados por esses estudos para os governos locais brasileiros. Por isso, este estudo avança e inclui aspectos político-eleitorais como variáveis de interesse. Assim, o objetivo desta pesquisa é analisar a influência dos aspectos socioeconômicos, financeiroorçamentários e político-eleitorais na transparência ativa e passiva dos governos locais brasileiros.

\section{FUNDAMENTAÇÃO TEÓRICA}

A transparência envolve a divulgação de informações por parte de uma organização que possibilita aos agentes externos monitorar e avaliar seu funcionamento interno e seu desempenho. A transparência pode ser desenvolvida proativamente, denominada transparência ativa, ou pode ser uma resposta às demandas de informação da sociedade, denominada transparência passiva (Grimmelikhuijsen \& Welch, 2012).

A transparência se torna fundamental em um ambiente democrático, as ações do governo devem ser transparentes e de conhecimento do povo, de modo que permita responsabilizá-los, cobrá-los e puni-los pelos atos que não melhorem as condições da sociedade (Cross, 1953). A liberdade da 
informação como lei tem sido adotada por diversos países (Cucciniello \& Nasi, 2014; Meijer, 2013), inclusive no Brasil, a partir da Lei n. 12.527 (Lei de Acesso à Informação, 2011).

A participação cidadão traz diversas vantagens, tanto para governos quanto para cidadãos (Irvin \& Stansbury, 2004), o envolvimento da sociedade pode melhorar os processos de decisão estratégica e produzir benefícios de eficiência para toda a sociedade (Randolph \& Bauer, 1999). Esse tipo de participação melhora a condução e as escolhas das políticas públicas, mas só se torna possível se existir a transparência das ações do governo para com a sociedade (Cucciniello \& Nasi, 2014).

As teorias relacionadas ao tema buscam explicar por que os políticos são encorajados a adotar as práticas mais transparentes (Alesina \& Perotti, 1996). Mais transparência minimiza o problema de risco moral ${ }^{1}$, facilitando o controle público, e isso diminui a corrupção. Tal constatação está alinhada com o pressuposto de que a probabilidade de um indivíduo cometer um crime depende do risco assumido, do possível ganho e da punição provável (Becker, 1968). Isto é, a transparência aumenta o risco do agente que comete algo ilícito ser pego (Sol, 2013).

Em relação aos fatores determinantes da transparência pública, existem diferentes incentivos para a divulgação de informações (Alcaide Muñoz, Rodríguez Bolívar, \& López Hernández, 2016). Neste estudo, agrupou-se em 3 categorias principais: a) condições socioeconômicas; b) condições financeiro-orçamentárias; e c) condições político-eleitorais.

Entre os aspectos socioeconômicos, uma das características que tem sido observada é o tamanho do município, mensurado pela população. Os custos de agência e o conflito de interesses com os cidadãos são mais evidentes em municípios com maior número de habitantes, o que se justifica pela presença de assimetria de informação entre políticos e cidadãos. Por isso, a divulgação de informação reduz esses custos de agência e a assimetria de informação, possibilitando que se avalie o desempenho dos gestores (Serrano-Cinca, Rueda-Tomás, \& Portillo-Tarragona, 2009; Zimmerman, 1977).

Entretanto, em um estudo realizado com os governos locais da Espanha, o qual discutia a transparência fiscal, não se obteve o mesmo resultado e observou-se uma relação negativa (EstellerMoré \& Otero, 2012). Dessa forma, tem-se a Hipótese 1:

H1: O número de habitantes exerce influência positiva sobre a transparência pública dos municípios brasileiros.

A renda municipal também é outro determinante. Em situações cuja renda municipal per capita é elevada, a população espera um melhor serviço e mais informações para confirmar que seus impostos estão sendo gastos de modo efetivo (Alcaide Muñoz et al., 2016; Cheng, 1992; Giroux, 1989; Ingram, 1984). Os gestores públicos têm o interesse de divulgar as demonstrações financeiras e outras informações públicas, com o objetivo de confirmar aos cidadãos a gestão das finanças públicas e influenciar as opiniões dos cidadãos sobre os impactos das políticas públicas (Alcaide Muñoz et al., 2016).

A renda municipal deve ser associada positivamente com a transparência pública, porque fornece um sinal de qualidade de gestão, o qual beneficia os políticos locais, aumenta suas chances de reeleição

\footnotetext{
${ }^{1}$ Risco moral (moral hazard): possibilidade de um agente econômico mudar seu comportamento de acordo com os diferentes contextos nos quais ocorrem as transações econômicas.
} 
e diminui os custos de agência (Gandía \& Archidona, 2008). Apesar disso, um estudo realizado em municípios da Itália e Espanha observou associação negativa (Guillamón, Ríos, Gesuele, \& Metallo, 2016). Dessa forma, propõe-se a Hipótese 2:

H2: A renda municipal exerce influência positiva sobre a transparência pública dos municípios brasileiros.

Uma população com nível de educação elevada exercerá pressão sobre as administrações públicas para divulgar informações, o que elevará o nível de transparência (Guillamón et al., 2016), sugerindo uma influência positiva. Entretanto, essa mesma relação não foi significativa em outros estudos realizados na Espanha, em países da Organização para a Cooperação e Desenvolvimento Econômico (OCDE) e na Itália (Caba Perez, Rodríguez Bolívar, \& López Hernández, 2014; Guillamón et al., 2016; Serrano-Cinca et al., 2009). As diferenças na cultura administrativa, no regime contábil e no próprio nível de governo (Alcaide Muñoz et al., 2016) podem explicar esses resultados. Desse modo, tem-se a Hipótese 3:

H3: O nível de desenvolvimento educacional exerce influência positiva sobre a transparência pública dos municípios brasileiros.

A região onde se localiza o município também pode ser um determinante da transparência, principalmente no caso brasileiro, em que se percebe uma vasta extensão territorial, com situações socioeconômicas muito distintas entre as regiões. Por isso, espera-se que essa relação seja distinta entre as diferentes regiões geográficas brasileiras. Na literatura também se observou que com municípios de diferentes países se utilizou uma variável de controle para distinguir as diferentes regiões considerando os aspectos econômicos de cada uma (Gallego-Álvarez, Rodríguez-Domínguez, \& García-Sánchez, 2010). Desse modo, propõe-se a Hipótese 4:

H4: A região exerce influência positiva sobre a transparência pública dos municípios brasileiros.

As condições financeiro-orçamentárias estão relacionadas à necessidade dos governos implementarem estruturas e práticas com o objetivo de demonstrar que estão cumprindo seu dever de transparência e responsabilidade sobre o uso dos recursos públicos (Alcaide Muñoz et al., 2016). Assim, busca-se verificar o efeito da condição financeira, da dívida, das transferências intergovernamentais e dos investimentos de capital dos municípios sobre a transparência pública.

A condição financeira municipal do governo está positivamente relacionada à motivação dos gestores para fornecer informações públicas (Alcaide Muñoz et al., 2016; Ingram, 1984). Essa variável representa a credibilidade financeira (Ingram, 1984), assim como reflete a capacidade do governo atender a seus compromissos de pagamento de dívidas (Giroux \& Deis, 1993). Os gestores públicos são encorajados a divulgar informações financeiras públicas como um mecanismo para permitir que suas ações sejam monitoradas (Cárcaba García \& García García, 2010).

Há estudos que encontraram relação negativa com a situação financeira no Brasil (Fiirst, Costa, Baldissera, \& Dall'Asta, 2017), ou até não conseguiram comprovar a variação dessa situação financeira do ente público com a transparência pública, nos governos locais dos Estados Unidos da América (EUA) (Giroux, 1989), nos governos locais da Itália e da Espanha (Guillamón et al., 2016) e também nos governos locais espanhóis (Serrano-Cinca et al., 2009). Entretanto, espera-se que municípios 
brasileiros cuja situação esteja melhor irão mostrar-se mais transparentes. Tendo isso em vista, temse, então, a Hipótese 5:

H5: A condição financeira municipal exerce influência positiva sobre a transparência pública dos municípios brasileiros.

A dívida é outra variável de interesse deste estudo. Mais altos níveis de dívida diminuem a capacidade do governo atender às demandas por serviços (Rodríguez Bolívar, Alcaide Muñoz, \& López Hernández, 2013). Os gestores públicos diminuem a dívida porque isso diminui os impostos sobre a propriedade, os quais são refletidos em mais votos para os políticos (Caba Perez et al., 2014), e, além disso, para reduzir os custos dos empréstimos, o que tende a aumentar o bem-estar desse político (Caba Perez et al., 2014; Zimmerman, 1977).

Os gestores são motivados a diminuir a dívida e fornecer informações para facilitar o monitoramento de suas ações (Laswad, Fisher, \& Oyelere, 2005), o que sugeriria uma relação positiva (Ríos, Benito, \& Bastida, 2013). Entretanto, essa relação não é consistente em todos os estudos, alguns já obtiveram evidências de uma relação negativa (Alt \& Lassen, 2006; Caba Perez et al., 2014; Cheng, 1992; Smith, 2004). A relação negativa se justifica pelo fato de que seria um meio de avaliar a responsabilidade e a eficácia dos órgãos governamentais, especialmente quando o nível da dívida é baixo (Caba Perez et al., 2014). Desse modo, propõe-se a Hipótese 6:

H6: A dívida municipal exerce influência negativa sobre a transparência pública dos municípios brasileiros.

A dependência de recursos de transferências intergovernamentais exige que o destinatário divulgue mais informações para justificar o uso das transferências recebidas, demonstrando que as escolhas dos gestores públicos estejam de acordo com suas responsabilidades (Alcaide Muñoz et al., 2016; Rodríguez Bolívar et al., 2013). Entretanto, essa relação pode ser contrária. O aumento nos recebimentos de recursos intergovernamentais estimula um aumento desproporcional do gasto no ente receptor (flypaper effect) (Mota, Diniz, \& Santos, 2017). Desse modo, propõe-se a Hipótese 7:

H7: As transferências intergovernamentais exercem influência positiva sobre a transparência pública dos municípios brasileiros.

O senso comum leva a crer que políticos, quando realizam obras públicas, tendem a tornar isso claro para toda a sociedade. Essa ideia está em linha com os aspectos teóricos e as evidências empíricas relacionadas aos investimentos de capital, exceto por um estudo no Brasil que não obteve associação significativa (Fiirst et al., 2017). Os esforços de investimento significativos em projetos públicos impactam de modo positivo os cidadãos. Por isso, os gestores públicos se envolvem em projetos com investimentos significativos e utilizam a transparência para divulgar esse tipo de informação (Cárcaba García \& García García, 2010). Assim, propõe-se a Hipótese 8:

H8: O investimento de capital exerce influência positiva sobre a transparência pública dos municípios brasileiros. 
A divulgação das informações pode ser uma técnica utilizada para mitigar problemas entre partidos políticos de oposição, assim como a capacidade de influenciar a manutenção no poder ou na reeleição. Por essa razão é que o uso das variáveis competição política, orientação política e coligação partidária tem consagrado-se nos estudos. O mandato eleitoral ainda não foi uma variável abordada em outros estudos como determinante da transparência.

A competição política é uma variável de interesse deste estudo. Os políticos ignoram suas promessas pré-eleitorais após assumirem o cargo, dando prioridade aos seus próprios interesses e desconsiderando o bem público, já que eles têm consciência da dificuldade dos cidadãos exercerem o controle efetivo da gestão pública (Alcaide Muñoz et al., 2016; Cárcaba García \& García García, 2010).

Uma forte oposição exige uma gestão responsável, caso contrário avisará aos cidadãos de quaisquer divergências de seu programa eleitoral (Alcaide Muñoz et al., 2016; Giroux, 1989; Serrano-Cinca et al., 2009). Portanto, quanto maior for a competição política, mais incentivo tem o gestor para cumprir suas promessas pré-eleitorais (Alcaide Muñoz et al., 2016; Baber, 1983; Caba Pérez, Rodríguez Bolívar, \& López Hernández, 2008; Gandía \& Archidona, 2008).

Ainda que se observem estudos que não tenham comprovado a relação significativa (Caba Pérez et al., 2008; García-Sánchez, Frías-Aceituno, \& Rodríguez-Domínguez, 2013; Laswad et al., 2005; Serrano-Cinca et al., 2009; Smith, 2004), ou até contrária à transparência (Cheng, 1992; Esteller-Moré \& Otero, 2012; Ríos et al., 2013), a maior parte da literatura se direciona para a associação positiva (Alcaide Muñoz et al., 2016; Caba Perez et al., 2014; Cárcaba García \& García García, 2010; GallegoÁlvarez et al., 2010; Gandía \& Archidona, 2008; Ingram, 1984; Rodríguez Bolívar et al., 2013). Essa diversidade de resultado se justifica pelas diferenças institucionais e econômicas de cada governo (Puron-Cid \& Bolívar, 2018). Desse modo, propõe-se a Hipótese 9:

H9: A competição política exerce influência positiva sobre a transparência pública dos municípios brasileiros.

As discussões quanto à orientação mais à esquerda ou mais à direita do espectro político também estão presentes no tema da transparência. Partidos mais à esquerda favorecem o aumento da despesa pública, enquanto os mais à direita visam a reduções orçamentárias. Entretanto, a direção da influência depende da natureza da informação do governo local em jogo e do partido no poder nesse momento (Piotrowski \& Van Ryzin, 2007).

Evidências anteriores indicam que partidos mais à esquerda apresentam maior nível de transparência (Caamaño-Alegre, Lago-Peñas, Reyes-Santias, \& Santiago-Boubeta, 2013; Sol, 2013) e partidos mais à direita, consequentemente, tem menor nível de transparência (García-Sánchez et al., 2013; Guillamón, Bastida, \& Benito, 2011; Ríos et al., 2013). Desse modo, propõe-se a Hipótese 10:

H10a: A orientação política mais à direita exerce influência negativa sobre a transparência pública dos municípios brasileiros.

H10b: A orientação política mais à esquerda exerce influência positiva sobre a transparência pública dos municípios brasileiros.

A coligação partidária entre os governos está associada à estabilidade política. Essa estabilidade pode levar ao avanço das atividades relacionadas ao governo, o qual só torna possível de ocorrer 
caso o governo se mostre transparente, caso contrário, não conseguiria recursos para avançar em suas políticas públicas (Gallego-Álvarez et al., 2010). Essa coincidência de orientação política entre diferentes níveis de governo pode retratar uma dimensão política que incentiva a divulgação (Puron-Cid \& Bolívar, 2018).

Entretanto, apesar das evidências empíricas serem inconclusivas (Gallego-Álvarez et al., 2010; Puron-Cid \& Bolívar, 2018; Serrano-Cinca et al., 2009), outro estudo demonstrou associação significativa, mas negativa (Caamaño-Alegre et al., 2013). Dessa forma, tem-se a Hipótese 11:

H11: A coligação partidária exerce influência negativa e significativa sobre a transparência pública dos municípios brasileiros.

A última variável representa o mandato eleitoral. Dado o pressuposto de que os gestores se comportam de modo oportunista, espera-se que aqueles que estão em seu primeiro mandato tenham mais incentivos para se comportar dessa forma em comparação àqueles que estão em seu segundo mandato (Rogoff, 1990).

Os gestores que proporcionam maiores retornos no primeiro mandato têm mais chances de ser reeleitos (Besley \& Case, 1995). Evidências anteriores confirmam que quando os governantes são candidatos à reeleição, a atividade econômica é maior e os impostos são menores (Alt, Mesquita, \& Rose, 2011). Dado esse comportamento, espera-se que os políticos sejam incentivados a divulgar informações de suas boas-práticas de gestão no primeiro mandato para reeleitos para o próximo mandato. Assim, propõe-se a Hipótese 12:

H12: O mandato eleitoral exerce influência positiva e significativa sobre a transparência pública dos municípios brasileiros.

\section{METODOLOGIA}

\subsection{Amostra da pesquisa}

Este estudo investigou os governos locais brasileiros, uma vez que estes estejam mais próximos da sociedade e que, por isso, o comportamento do gestor pode estar relacionado ao controle realizado pela sociedade (Sol, 2013). Dessa forma, o universo representa os 5.570 municípios brasileiros.

Para selecionar a amostra desta pesquisa, alguns municípios foram excluídos, pois não apresentavam dados em uma ou mais das variáveis utilizadas neste estudo e, em outros casos, os dados gerados pelo município apresentavam inconsistências. Ao final, obteve-se 3.550 municípios.

\subsection{Definição das variáveis}

As variáveis relacionadas à transparência foram obtidas do Ranking Nacional de Transparência realizado pelo Ministério Público Federal (MPF, n.d.). Esse índice de transparência é baseado na observância pelos municípios aos requisitos de Transparência Ativa (20 itens avaliados; alfa de Cronbach $=0,93$ ), Transparência Passiva (10 itens avaliados; alfa de Cronbach $=0,89$ ) e Boas Práticas de Transparência ( 2 itens avaliados; alfa de Cronbach $=0,57$ ). 
Observa-se por meio do alfa de Cronbach que, com exceção das Boas Práticas de Transparência, uma vez que tem apenas 2 itens avaliados, todos os demais demonstraram alta confiabilidade interna nos itens avaliados, de modo que o índice avaliado reflete a transparência de cada município.

Cada item tem um peso diferente na composição total do índice de transparência do município, de modo que considera o impacto desse item em relação à transparência como um todo.

Esse índice foi elaborado pelas instituições de controle e é baseado essencialmente nas exigências legais (Constituição da República Federativa do Brasil [CF], 1988; Lei Complementar n. 101 [Lei de Responsabilidade Fiscal], 2000; Decreto n. 7.185, 2010; Lei de Acesso à Informação, 2011; Supremo Tribunal Federal [STF], 2015), à exceção dos itens relacionados às "Boas Práticas de Transparência", que incluem itens não obrigatórios, mas considerados divulgação voluntária.

Trata-se de um índice abrangente e que inclui as diferentes exigências legais às quais os municípios estão submetidos, por isso sua avaliação final representa a transparência obrigatória (ativa e passiva) e voluntária (boas práticas) do município.

As variáveis independentes se referem às condições socioeconômicas, financeiro-orçamentárias e político-eleitorais. O grupo das variáveis socioeconômicas, representadas pelo número de habitantes, renda per capita e região, foram coletadas no site do Instituto Brasileiro de Geografia e Estatística (IBGE, 2010). Para avaliar o nível de desenvolvimento educacional foram utilizados os dados da Federação das Indústrias do Estado do Rio de Janeiro (FIRJAN, n.d.). As variáveis financeiro-orçamentárias foram obtidas no site da Secretaria do Tesouro Nacional (STN, n.d.). Por fim, as variáveis políticoeleitorais foram obtidas a partir do portal do Tribunal Superior Eleitoral (TSE, n.d.). A definição, mensuração e descrição de cada uma das variáveis são expostas no Quadro 1.

\section{QUADRO 1 DEFINIÇÃO DAS VARIÁVEIS DO ESTUDO}

\begin{tabular}{|c|c|c|c|c|}
\hline Variável & Código & Mensuração & Descrição & Ano \\
\hline \multicolumn{5}{|c|}{ VARIÁVEIS DEPENDENTES } \\
\hline \multicolumn{5}{|c|}{ TRANSPARÊNCIA } \\
\hline $\begin{array}{l}\text { Transparência } \\
\text { Geral }\end{array}$ & $\mathrm{TG}$ & $\begin{array}{c}\text { Checklist, que envolve regulamentação } \\
\text { LAl, LRF e LT. }\end{array}$ & $\begin{array}{l}\text { Indicador que tem o objetivo de avaliar } \\
\text { o grau de cumprimento de dispositivos } \\
\text { legais quanto à transparência. }\end{array}$ & 2016 \\
\hline $\begin{array}{l}\text { Transparência } \\
\text { Ativa }\end{array}$ & $\mathrm{TA}$ & $\begin{array}{l}\text { Informações gerais; receita; despesa; } \\
\text { licitações e contratos; relatórios. }\end{array}$ & $\begin{array}{c}\text { Envolve aspectos relacionados } \\
\text { à divulgação de informações } \\
\text { independentemente de requerimento } \\
\text { dos cidadãos. }\end{array}$ & 2016 \\
\hline $\begin{array}{l}\text { Transparência } \\
\text { Passiva }\end{array}$ & $\mathrm{TP}$ & $\begin{array}{l}\text { Serviço de Informações ao Cidadão } \\
\text { (SIC); Serviço Eletrônico de Informações } \\
\text { ao Cidadão (e-SIC); Divulgação da } \\
\text { estrutura e forma de contato. }\end{array}$ & $\begin{array}{c}\text { Envolve aspectos relacionados a } \\
\text { divulgação de informações para } \\
\text { atender aos requerimentos dos } \\
\text { cidadãos. }\end{array}$ & 2016 \\
\hline $\begin{array}{l}\text { Boas Práticas de } \\
\text { Transparência }\end{array}$ & $\mathrm{BPT}$ & $\begin{array}{l}\text { Remuneração individualizada por } \\
\text { agente público; diária e passagens } \\
\text { individualizado e completo. }\end{array}$ & $\begin{array}{l}\text { Envolve aspectos não obrigatórios, } \\
\text { mas que atendem a boas práticas de } \\
\text { transparência. }\end{array}$ & 2016 \\
\hline
\end{tabular}




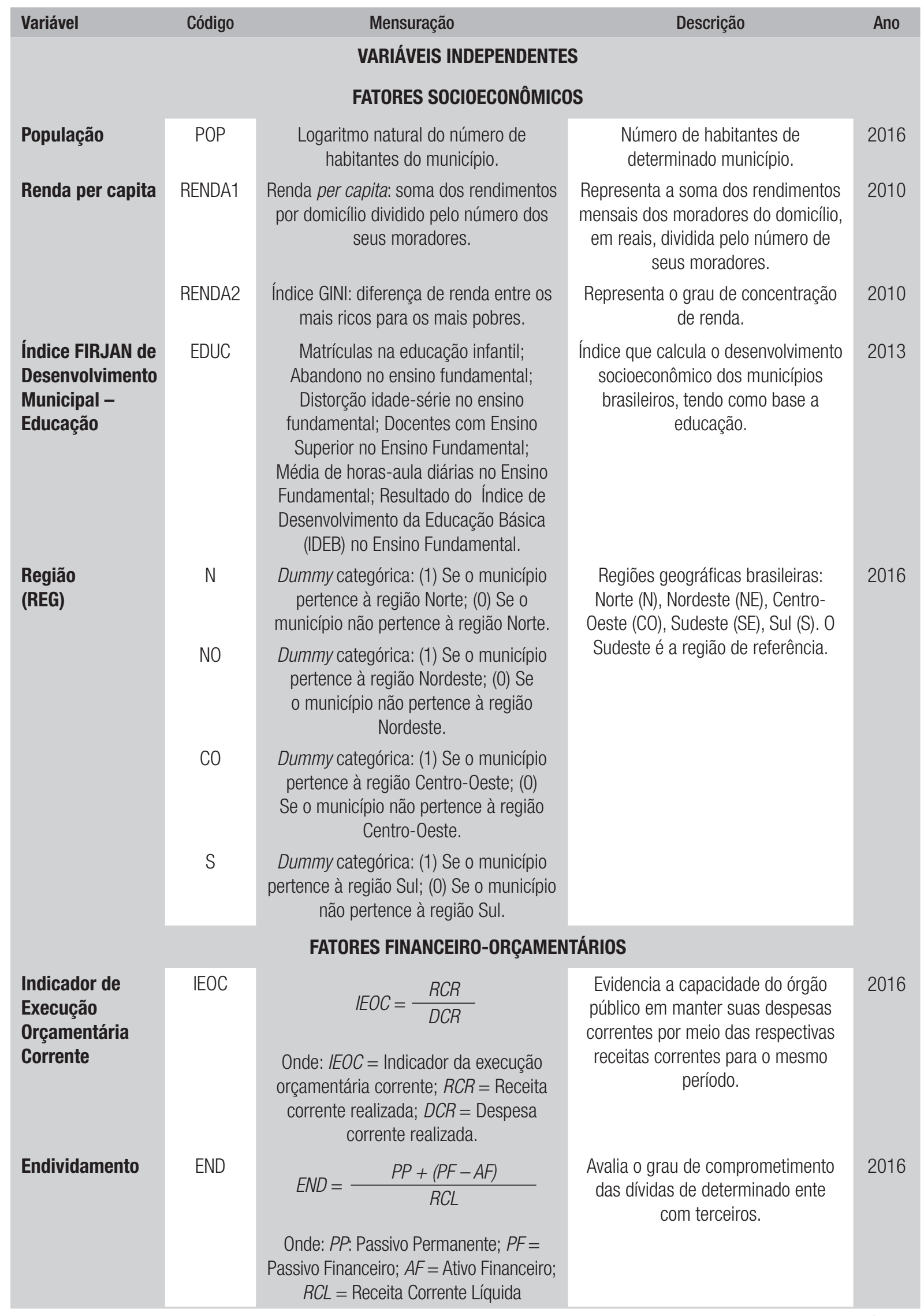




\begin{tabular}{|c|c|c|c|c|}
\hline Variável & Código & Mensuração & Descrição & Ano \\
\hline \multirow[t]{5}{*}{$\begin{array}{l}\text { Indicador } \\
\text { do Grau de } \\
\text { Dependência }\end{array}$} & IGD & $I G D=\frac{T I}{R T}$ & $\begin{array}{l}\text { Indica o grau de dependência da } \\
\text { administraçãa municipal em relação } \\
\text { às transferências recebidas. }\end{array}$ & 2016 \\
\hline & & $\begin{array}{c}\text { Onde: } T I=\text { Receita de Transferência } \\
\text { Intergovernamentais; } R T=\text { Receita Total }\end{array}$ & & \\
\hline & IGDu & $\begin{array}{c}\qquad G D=\frac{T U}{R T} \\
\text { Onde: } T U=\text { Receita de Transferência da } \\
\text { União; } R T=\text { Receita Total }\end{array}$ & $\begin{array}{c}\text { Indica o grau de dependência da } \\
\text { administração municipal em relação } \\
\text { às transferências recebidas da } \\
\text { União. }\end{array}$ & 2016 \\
\hline & IGDe & $\begin{array}{c}\qquad G D=\frac{T E}{R T} \\
\text { Onde: TE = Receita de Transferência dos } \\
\text { Estados; } R T=\text { Receita Total }\end{array}$ & $\begin{array}{c}\text { Indica o grau de dependência da } \\
\text { administração municipal em relação } \\
\text { às transferências recebidas dos } \\
\text { estados. }\end{array}$ & 2016 \\
\hline & IGDM & $\begin{array}{c}\qquad G D=\frac{T M}{R T} \\
\text { Onde: TM = Receita de Transferência } \\
\text { Multigovernamentais; } R T=\text { Receita Total }\end{array}$ & $\begin{array}{c}\text { Indica o grau de dependência } \\
\text { da administração municipal em } \\
\text { relação às transferências recebidas } \\
\text { multigovernamentais. }\end{array}$ & 2016 \\
\hline \multirow[t]{3}{*}{$\begin{array}{l}\text { Indicador de } \\
\text { Despesas com } \\
\text { Investimento }\end{array}$} & IDI & $|D|=\frac{G l}{R C L}$ & $\begin{array}{l}\text { Indica a relação entre as Despesas } \\
\text { de Investimento e a Receita Corrente } \\
\text { Líquida. }\end{array}$ & 2016 \\
\hline & & $\begin{aligned} \text { Onde: } G I & =\text { Gastos de Investimento; } R C L \\
& =\text { Receita Corrente Líquida }\end{aligned}$ & & \\
\hline & & \multicolumn{2}{|c|}{ FATORES POLÍTICO-ELEITORAIS } & \\
\hline $\begin{array}{l}\text { Competição } \\
\text { Política }\end{array}$ & $\mathrm{CP}$ & $\begin{array}{c}C P=\frac{1}{\sum_{i=1}^{n} p_{i}^{2}} \\
\text { Onde: } p=\text { proporçõoes de votos obtidos } \\
\text { por cada prefeito nas eleições }\end{array}$ & $\begin{array}{c}\text { Define o grau de fragmentação do } \\
\text { sistema partidário ponderando a } \\
\text { força relativa das legendas que } 0 \\
\text { compõem. }\end{array}$ & 2016 \\
\hline \multirow[t]{2}{*}{$\begin{array}{l}\text { Orientação } \\
\text { Política } \\
\text { (OP) }\end{array}$} & ESQ & $\begin{array}{l}\text { Dummy: (1) Se o partido político do } \\
\text { governador é mais à esquerda. (0) Caso } \\
\text { contrário. }\end{array}$ & $\begin{array}{c}\text { Orientação política dos partidos } \\
\text { políticos dos respectivos prefeitos } \\
\text { municipais. }\end{array}$ & 2016 \\
\hline & DIR & $\begin{array}{l}\text { Dummy: (1) Se o partido político do } \\
\text { governador é mais à direita. (0) Caso } \\
\text { contrário. }\end{array}$ & $\begin{array}{l}\text { Mais à Esquerda: PT, PSB, PPS, PDT, } \\
\text { PMN, PV e PC do B. Centro: PMDB, } \\
\text { PSDB e PTB. Mais à Direita: PFL, } \\
\text { PL, PSD, PSC, Prona, PSL, PST, PP e } \\
\text { DEM (Klein \& Sakurai, 2015). }\end{array}$ & \\
\hline \multirow[t]{2}{*}{$\begin{array}{l}\text { Coligação } \\
\text { Partidária (CPart) }\end{array}$} & СРP & $\begin{array}{l}\text { Dummy: (1) Se o partido do prefeito } \\
\text { pertence à coligação partidária do } \\
\text { presidente. (0) Caso contrário. }\end{array}$ & $\begin{array}{l}\text { Verifica se o partido do prefeito } \\
\text { pertence à coligação partidária do } \\
\text { presidente. }\end{array}$ & 2016 \\
\hline & CPG & $\begin{array}{l}\text { Dummy: (1) Se o partido do prefeito } \\
\text { pertence à coligação partidária do } \\
\text { governador. (0) Caso contrário. }\end{array}$ & $\begin{array}{c}\text { Verifica se o partido do prefeito } \\
\text { pertence à coligação partidária do } \\
\text { governador. }\end{array}$ & \\
\hline $\begin{array}{l}\text { Mandato } \\
\text { Eleitoral }\end{array}$ & ME & $\begin{array}{l}\text { Dummy: (1) Prefeito do município exerce } \\
\text { o primeiro mandato eleitoral. (0) Caso } \\
\text { contrário. }\end{array}$ & $\begin{array}{l}\text { Verifica se o prefeito do município } \\
\text { exerce o primeiro mandato eleitoral. }\end{array}$ & 2016 \\
\hline
\end{tabular}

Fonte: Elaborado pelos autores. 


\subsection{Modelo econométrico}

Utilizou-se a técnica de análise multivariada, a qual permite explorar o desempenho conjunto das variáveis e determinar a influência ou a importância de cada uma, estando as demais presentes. Utilizou-se o método de regressão linear múltipla como técnica estatística para esta pesquisa, por meio do método dos mínimos quadrados ordinários (MQO). Como as variáveis testadas se referem a diferentes municípios em um mesmo período, utilizou-se a técnica de dados de seção transversal (cross-section). Para tanto, tem-se a Equação 1, a qual é subdividida de acordo com a variável dependente:

$Y_{i}=\beta_{1 i}+\beta_{2} P O P_{i}+\beta_{3} R E N D A 1_{i}+\beta_{4} R_{E N D A 2_{i}}+\beta_{5} E D U C_{i}+\beta_{6} N_{i}+\beta_{7} N E_{i}+\beta_{8} C O 1_{i}+\beta_{9} S_{i}+\beta_{10} I E O C_{i}$ $+\beta_{11} E N D_{i}+\beta_{12} I G D_{i}+\beta_{13} I G D u_{i}+\beta_{14} I G D e_{i}+\beta_{15} I G D m_{i}+\beta_{16} I D I_{i}+\beta_{17} C P_{i}+\beta_{18} E S Q_{i}+\beta_{19} D I R_{i}+$ $\beta_{20} C P P_{i}+\beta_{21} C P G_{i}+\beta_{22} M E_{i}+\varepsilon_{i}$

Por meio desses testes foi possível observar e analisar a determinação da variável transparência em função das variáveis independentes. Para a análise dos dados, estes foram organizados em uma planilha do software MS Excel para, então, submeter a softwares específicos de análise quantitativa, como o software $R$. O tratamento estatístico dos dados, além da reamostragem, utiliza técnicas de análise bivariada e multivariada.

Dada a necessidade de melhorar a confiabilidade e a robustez dos resultados, optou-se por realizar o método de reamostragem, uma vez que se almeja reconhecer um fenômeno cuja modelagem matemática é complexa a partir de dados transversais.

A reamostragem repetiu 100.000 vezes a amostra e possibilitou obter uma amostra de estimação e de validação, das quais fosse possível obter coeficientes que representassem a relação estimada.

Desse modo, pôde-se encontrar uma solução melhor fazendo 100.000 simulações para deixar a amostra mais robusta. Dessa amostra, separou-se em 2 grupos, $70 \%$ de estimação para rodar o modelo e 30\% de teste, utilizados para testar a previsibilidade do modelo.

\section{DESCRIÇÃO E ANÁLISE DOS RESULTADOS}

\subsection{Descrição dos resultados}

As variáveis dependentes foram divididas em 4 perspectivas: a) Transparência Geral; b) Transparência Ativa; c) Transparência Passiva; e d) Boas Práticas de Transparência. Para a realização da reamostragem e o teste de regressão, excluíram-se os municípios que continham dados outliers para cada equação, uma vez que a utilização deles poderia prejudicar a confiabilidade e a capacidade de previsão dos resultados.

A reamostragem proporcionou resultados mais robustos e o melhor modelo preditivo para os dados selecionados, os quais são sintetizados na Tabela 1 . 
RAP | Influência dos aspectos socioeconômicos, financeiro-orçamentários e político-eleitorais na transparência dos governos locais

\begin{tabular}{|c|c|c|c|c|c|c|c|c|c|c|c|c|c|c|c|c|c|}
\hline & $\frac{\pi}{0}$ & $\begin{array}{l}\text { 今े } \\
\text { L్ }\end{array}$ & 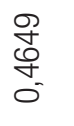 & $\begin{array}{l}\text { 守 } \\
0 \\
0 \\
0\end{array}$ & & $\begin{array}{l}\text { 今े } \\
\text { م⿱ } \\
\text { 今̀ }\end{array}$ & $\begin{array}{l}8 \\
8 \\
0\end{array}$ & $\begin{array}{l}\text { O⿱丶万仒 } \\
\text { ․ }\end{array}$ & $\begin{array}{l}\widetilde{\sigma} \\
\text { ठ } \\
\text { - }\end{array}$ & \begin{tabular}{l}
0 \\
\multirow{N}{0}{} \\
0 \\
0
\end{tabular} & $\begin{array}{l}8 \\
8 \\
0\end{array}$ & $\begin{array}{l}0 \\
0 \\
0 \\
0 \\
0\end{array}$ & $\begin{array}{l}\mathscr{8} \\
\mathscr{D} \\
0 \\
0 \\
0\end{array}$ & $\begin{array}{l}5 \\
8 \\
8 \\
0\end{array}$ & $\begin{array}{l}\text { N } \\
\overline{2} \\
0 \\
0\end{array}$ & $\begin{array}{l}8 \\
0 \\
0 \\
0 \\
0\end{array}$ & \\
\hline & 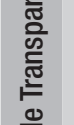 & : & $\begin{array}{l}8 \\
8 \\
\stackrel{5}{0} \\
0\end{array}$ & $\frac{\bar{N}}{\stackrel{N}{N}}$ & ¿ & $\frac{\pi}{\frac{\pi}{5}}$ & $\begin{array}{l}8 \\
8 \\
0\end{array}$ & $\begin{array}{l}\text { D } \\
\text { है } \\
0 \\
0\end{array}$ & $\begin{array}{l}8 \\
8 \\
0\end{array}$ & $\begin{array}{l}\stackrel{0}{o} \\
\stackrel{+}{5} \\
0\end{array}$ & $\begin{array}{l}8 \\
8 \\
0\end{array}$ & $\underset{\substack{n \\
0}}{\stackrel{10}{N}}$ & $\begin{array}{l}\mathscr{8} \\
\stackrel{ల}{1} \\
0\end{array}$ & $\begin{array}{l}\stackrel{?}{N} \\
\stackrel{0}{0}\end{array}$ & $\begin{array}{l}\mathscr{\infty} \\
\stackrel{\infty}{+} \\
0\end{array}$ & $\begin{array}{l}\text { oे } \\
\text { ठ } \\
0^{-}\end{array}$ & \\
\hline & 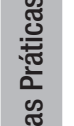 & 今े & 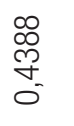 & 胥 & $>$ & 高 & $\begin{array}{l}8 \\
8 \\
0\end{array}$ & $\begin{array}{l}8 \\
8 \\
8 \\
0\end{array}$ & 8. & $\begin{array}{l}8 \\
8 \\
0 \\
0\end{array}$ & $\begin{array}{l}8 \\
8 \\
0\end{array}$ & $\begin{array}{l}\mathscr{N} \\
\stackrel{\mathbb{N}}{\sigma} \\
0\end{array}$ & 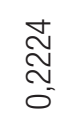 & 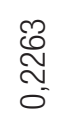 & 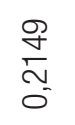 & $\begin{array}{l}8 \\
8 \\
0\end{array}$ & \\
\hline & & & & & & & о & $\begin{array}{l}\overline{\widetilde{\pi}} \\
\overline{0} \\
\widetilde{\sigma}\end{array}$ & $z$ & 㞱 & $\infty$ & 으 & 总 & 岕 & E్ & $\overline{\underline{ }}$ & \\
\hline & & 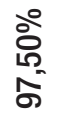 & $\begin{array}{l}\text { Эั } \\
\frac{0}{0}\end{array}$ & $\begin{array}{l}\bar{N} \\
\frac{1}{50} \\
0\end{array}$ & & $\begin{array}{l}\text { 。े } \\
\text { م⿱ 口̊ }\end{array}$ & 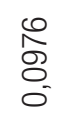 & $\begin{array}{l}8 \\
8 \\
0\end{array}$ & \& & 8 & $\begin{array}{l}\hat{\approx} \\
8 \\
0\end{array}$ & $\begin{array}{l}8 \\
8 \\
0\end{array}$ & $\frac{\widetilde{O}}{0}$ & $\begin{array}{l}8 \\
8 \\
0\end{array}$ & & & \\
\hline 㟔 & $\begin{array}{l}\frac{0}{0} \\
\frac{0}{0} \\
\frac{\pi}{0 .} \\
\frac{\pi}{0}\end{array}$ & : & $\begin{array}{l}\widehat{N} \\
\text { Oे } \\
0 \\
0\end{array}$ & $\begin{array}{l}\overline{\widetilde{J}} \\
\stackrel{\sigma}{\sigma} \\
\text { O- }\end{array}$ & 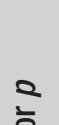 & 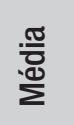 & 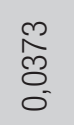 & $\begin{array}{l}8 \\
8 \\
0\end{array}$ & $\begin{array}{l}8 \\
8 \\
0 \\
0\end{array}$ & \& & $\begin{array}{l}\text { o } \\
\text { ᄋ } \\
0\end{array}$ & $\begin{array}{l}8 \\
8 \\
0\end{array}$ & $\begin{array}{l}20 \\
0 \\
0 \\
0\end{array}$ & $\begin{array}{l}8 \\
8 \\
0\end{array}$ & & & \\
\hline 옹 & 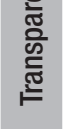 & $\begin{array}{l}\text { ○े } \\
\text { ஸे } \\
\text { ஸे }\end{array}$ & $\begin{array}{l}0 \\
0 \\
0 \\
0 \\
0\end{array}$ & \begin{tabular}{l}
$\hat{\tilde{d}}$ \\
\multirow{\sigma}{\sigma}{} \\
0
\end{tabular} & & 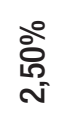 & $\begin{array}{l}\stackrel{2}{8} \\
8 \\
0\end{array}$ & $\begin{array}{l}8 \\
8 \\
0\end{array}$ & $\begin{array}{l}8 \\
8 \\
0\end{array}$ & 8 & $\begin{array}{l}8 \\
8 \\
0\end{array}$ & $\begin{array}{l}8 \\
8 \\
0\end{array}$ & $\begin{array}{l}\text { ஜ } \\
\text { ర్ }\end{array}$ & $\begin{array}{l}8 \\
8 \\
0\end{array}$ & & & \\
\hline 옹 & & & $\approx$ & $\begin{array}{l}\frac{\bar{d}}{\hbar} \\
D^{2}\end{array}$ & & & о & $\begin{array}{l}\bar{\pi} \\
\overline{0} \\
\overline{0} \\
\propto 1\end{array}$ & $z$ & 㞱 & ○ & $\infty$ & $\overline{\underline{ }}$ & $\begin{array}{l}\dot{\omega} \\
\dot{\bar{D}}\end{array}$ & & & \\
\hline 吝 & & $\begin{array}{l}\text { 今े } \\
\text { ద్ }\end{array}$ & $\begin{array}{l}\infty \\
\widetilde{N} \\
\infty \\
0 \\
0\end{array}$ & $\begin{array}{l}\bar{o} \\
\text { g̛ } \\
0\end{array}$ & & 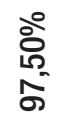 & $\underset{\substack{\mathbb{N} \\
\hdashline}}{\mathbb{N}}$ & 8 & $\begin{array}{l}\text { ₹ } \\
\infty \\
\stackrel{5}{0} \\
0\end{array}$ & 8 & 8 & $\begin{array}{l}\frac{2}{0} \\
\stackrel{0}{c} \\
0\end{array}$ & 8 & $\begin{array}{l}\bar{\sigma} \\
\infty \\
0 \\
0\end{array}$ & $\begin{array}{l}\widehat{D} \\
\infty \\
\overline{0}\end{array}$ & & \\
\hline 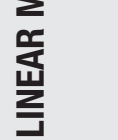 & 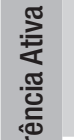 & 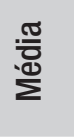 & 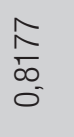 & 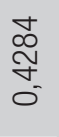 & 흐 & & 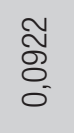 & 8. & \begin{tabular}{l}
0 \\
\multirow{0}{0}{} \\
0 \\
0
\end{tabular} & 8 & $\begin{array}{l}8 \\
8 \\
0\end{array}$ & 命 & $\begin{array}{l}8 \\
8 \\
0\end{array}$ & $\begin{array}{l}8 \\
8 \\
\\
0\end{array}$ & $\begin{array}{l}\hat{\widehat{O}} \\
\text { o }\end{array}$ & & \\
\hline 遮 & 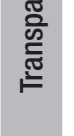 & 今े & $\frac{N}{\frac{N}{\infty}}$ & 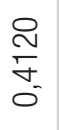 & $>$ & 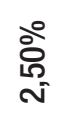 & $\begin{array}{l}\mathbb{\Xi} \\
\stackrel{\Xi}{O} \\
0\end{array}$ & 8. & $\begin{array}{l}\widetilde{\sigma} \\
\tilde{\delta} \\
\tilde{\sigma}\end{array}$ & 8 & 8 & \%ి & 8 & $\frac{0}{8}$ & $\begin{array}{l}8 \\
8 \\
0 \\
0\end{array}$ & & \\
\hline $\begin{array}{l}\text { 崩 } \\
\text { 㟔 } \\
\text { es o }\end{array}$ & & & $\approx$ & $\begin{array}{l}\bar{\Phi} \\
\stackrel{5}{\Sigma} \\
\nabla^{2}\end{array}$ & & & 용 & 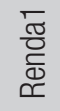 & $\begin{array}{l}\frac{\pi}{0} \\
\frac{0}{0} \\
\simeq\end{array}$ & 总 & 㞱 & 8 & $\infty$ & $\overline{\underline{ }}$ & $\begin{array}{l}\text { D } \\
0\end{array}$ & & \\
\hline 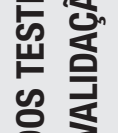 & & 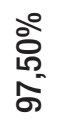 & $\begin{array}{l}\overline{5} \\
\square \\
\infty \\
0 \\
0\end{array}$ & 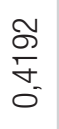 & & $\begin{array}{l}\text { 今े } \\
\text { L్ } \\
\text { 今 }\end{array}$ & $\frac{\widetilde{N}}{\frac{0}{0}}$ & $\begin{array}{l}8 \\
8 \\
0\end{array}$ & 8. & $\hat{\delta}$ & $\begin{array}{l}8 \\
8 \\
\circ\end{array}$ & $\begin{array}{l}\text { Oे } \\
\text { Oे } \\
0\end{array}$ & $\begin{array}{l}8 \\
8 \\
\circ\end{array}$ & $\begin{array}{l}\infty \\
\stackrel{\infty}{\approx} \\
0 \\
0\end{array}$ & $\begin{array}{l}10 \\
0 \\
0 \\
0 \\
0\end{array}$ & & 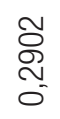 \\
\hline 㠰 & 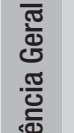 & 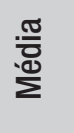 & $\begin{array}{l}\infty \\
\text { ल } \\
\infty \\
0 \\
0\end{array}$ & $\begin{array}{l}\overline{\widetilde{\sigma}} \\
\text { ơ } \\
\text { o. }\end{array}$ & 흐 & 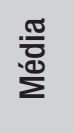 & 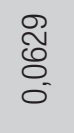 & $\begin{array}{l}8 \\
8 \\
0\end{array}$ & $\begin{array}{l}8 \\
8 \\
0\end{array}$ & \&े & $\begin{array}{l}8 \\
8 \\
0\end{array}$ & $\frac{m}{8}$ & 8 & $\begin{array}{l}\text { श्र } \\
\stackrel{0}{0} \\
0\end{array}$ & $\begin{array}{l}\text { ठ } \\
8 \\
0 \\
0\end{array}$ & & $\begin{array}{l}\text { ஜ్ } \\
\text { ष्. } \\
0\end{array}$ \\
\hline щّ & $\begin{array}{l}\text { o. } \\
\text { कू } \\
\text { 륜 }\end{array}$ & 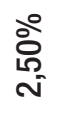 & $\begin{array}{l}\text { L } \\
\text { m } \\
0 \\
0\end{array}$ & 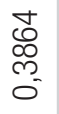 & 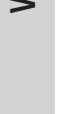 & $\begin{array}{l}\text { 。ें } \\
\text { ஸे } \\
\text { N }\end{array}$ & $\begin{array}{l}\text { Oे } \\
8 \\
0 \\
0\end{array}$ & $\begin{array}{l}8 \\
\text { O } \\
0\end{array}$ & $\begin{array}{l}8 \\
8 \\
\circ\end{array}$ & 8 & $\begin{array}{l}8 \\
8 \\
0\end{array}$ & $\begin{array}{l}8 \\
8 \\
0\end{array}$ & 8 & $\begin{array}{l}8 \\
8 \\
0\end{array}$ & $\begin{array}{l}8 \\
8 \\
0\end{array}$ & & $\frac{10}{8}$ \\
\hline 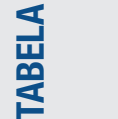 & & & $\approx$ & $\begin{array}{l}\bar{\Xi} \\
\overline{5}^{2}\end{array}$ & & & 홍 & $\begin{array}{l}\bar{\pi} \\
\frac{\pi}{0} \\
\stackrel{0}{0}\end{array}$ & 总 & $z$ & щu & 엉 & es & 므 & ป & $\stackrel{\frac{\Upsilon}{\bar{D}}}{ }$ & ல \\
\hline
\end{tabular}




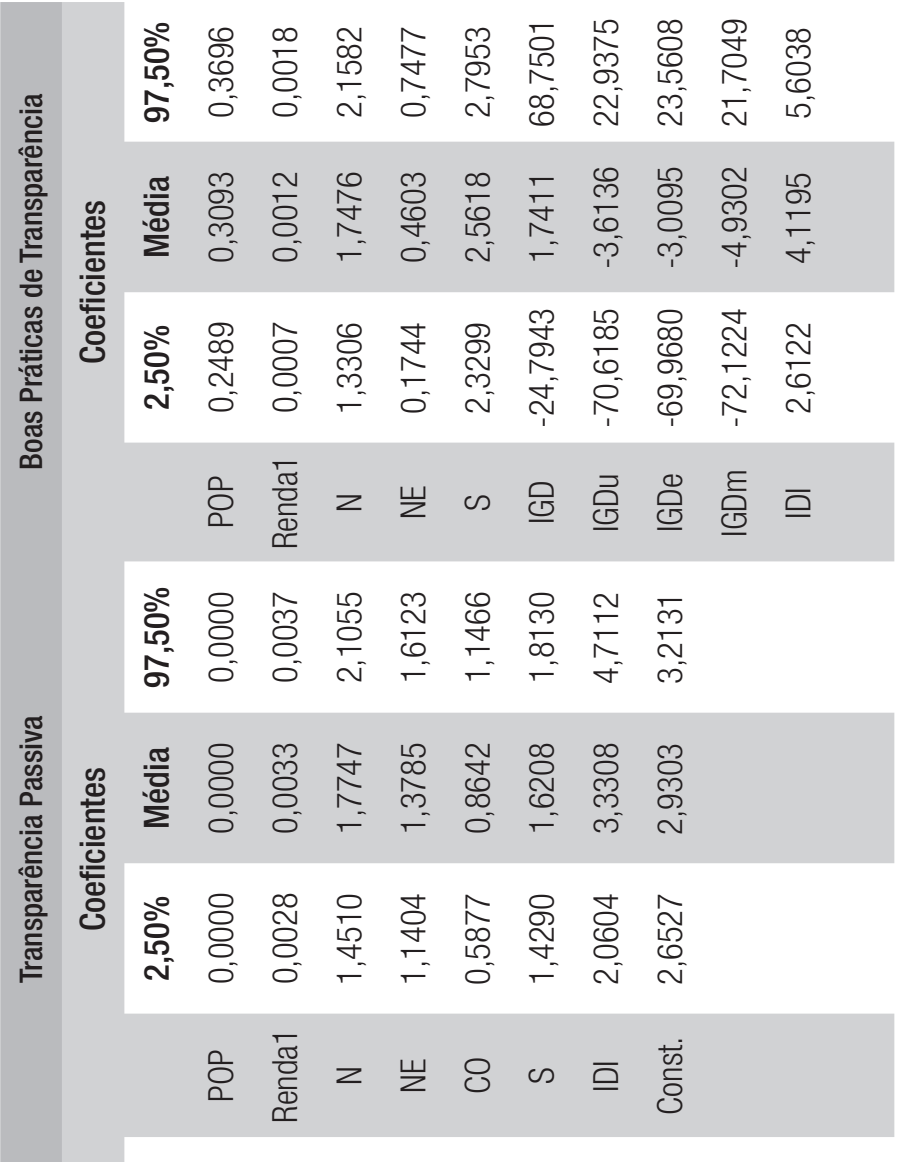

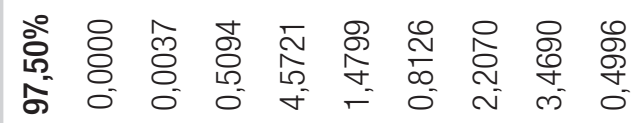

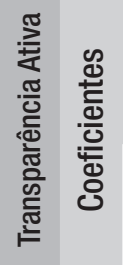

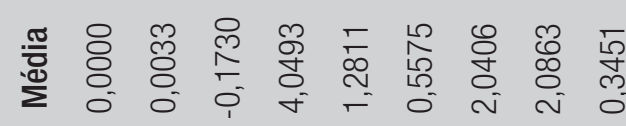

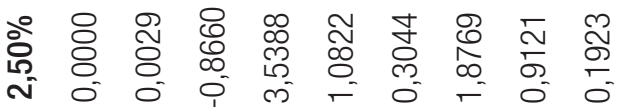

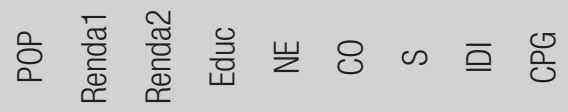

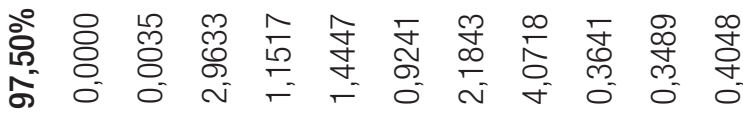

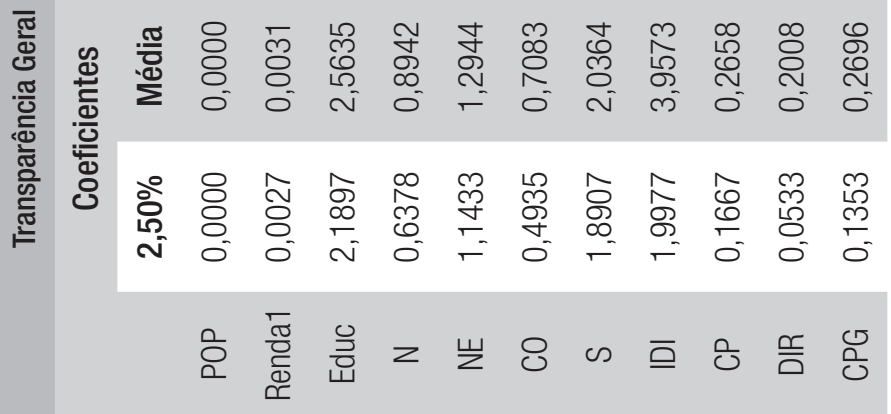


A Tabela 1 apresenta os resultados para a capacidade de explicação do modelo em relação aos dados que se conhece $\left(R^{2}\right)$, a capacidade de previsão na simulação de 100.000 amostras $\left(U_{2}\right.$ Theil), evidenciando a expectativa do erro. Por fim, também apresenta os resultados obtidos para a significância de cada variável (valor $p$ ) na equação que é colocada em teste, dentro da distribuição de probabilidade (2,50\%, média e 97,50\%), com os respectivos coeficientes.

Para as variáveis dependentes Transparência Geral, Transparência Ativa, Transparência Passiva e Boas Práticas de Transparência, após excluir os municípios com dados outliers, foram utilizadas 3.313, 3.273, 3.457 e 3.457 observações, respectivamente, em cada modelo. O $R^{2}$ médio, que representa a proporção de variação amostral da variável dependente explicada pelas variáveis independentes, o maior foi de 83,98\% para os dados conhecidos no modelo cuja dependente foi a Transparência Geral, já o menor foi quando se utilizou o modelo com a Transparência Passiva (9,27\%). Já o $U_{2}$ Theil que representa os dados não conhecidos, foi de 40,21\%, 42,84\%, 49,21\% e $74,71 \%$, respectivamente. Esses resultados indicam alto poder de previsão para os dados conhecidos e baixa expectativa de erro para os dados não conhecidos. Esse modelo não apresentou problemas de autocorrelação serial, confirmada no teste Durbin-Watson e não tem problemas de heterocedasticidade, confirmada no teste Box-Ljung.

Cada um dos modelos utilizados indicou diferentes resultados. A maior capacidade de previsão foi obtida quando comparadas as variáveis à Transparência Geral e à Transparência Ativa. Esse resultado pode justificar-se, uma vez que a transparência passiva representa diferentes incentivos ao gestor público, uma vez que ela só é observada por quem solicita informações ao poder público.

Observa-se que, entre as variáveis, os aspectos socioeconômicos são os que determinam o comportamento dos diferentes tipos de transparência, já entre as variáveis financeiro-orçamentárias, somente os gastos com investimentos foram determinantes para a Transparência Geral e as Boas Práticas de Transparência, enquanto que entre os fatores políticos somente a competição política foi significativa quando comparada à Transparência Geral.

\subsection{Discussão e implicações dos resultados}

Os resultados obtidos permitem aceitar as Hipóteses 1, 2, 3 e 4, ainda que em algumas situações não se tenha observado relação com todas as variáveis dependentes. Eles possibilitam confirmar que, para o caso dos governos municipais brasileiros, os aspectos socioeconômicos exercem um impacto positivo sobre a transparência. Já no que se refere aos aspectos financeiro-orçamentários, somente os investimentos de capital parecem exercer um impacto positivo sobre a transparência dos municípios brasileiros, o que permitiu aceitar a Hipótese 8. Por fim, a competição política também indicou exercer um impacto positivo sobre a Transparência Geral, permitindo aceitar a Hipótese 9.

O número de habitantes aponta um impacto positivo no nível de Transparência Passiva e de Boas Práticas de Transparência. Os resultados apresentados indicam que, para o aumento de 1 ponto no índice do número de habitantes, o impacto na Transparência Passiva é próximo de 0. Entretanto, caso se perceba um mesmo aumento, eleva-se o nível de Boas Práticas de Transparência em 0,3093 pontos. Esse resultado está em linha com a literatura, uma vez que grandes populações exigem mais serviços, a administração pública deve lidar com uma ampla variedade de stakeholders, os quais exigem a implementação de práticas de responsabilidade social e mais informações (García-Sánchez et al., 2013). 
A população exerce efeito positivo, uma vez que os conflitos de interesses são mais prováveis de ocorrer em municípios maiores, sendo a assimetria de informação ainda maior nesses municípios. A transparência, portanto, mostra-se uma ferramenta para diminuir os custos de agência e a assimetria de informação. Isso significa que a gestão municipal se torna mais fácil com a transparência, uma vez que diversas demandas da população serão atendidas de modo imediato a partir da transparência ativa e outras serão atendidas via solicitação (transparência passiva).

A renda municipal exerce efeito positivo sobre o nível de Transparência Geral, Transparência Ativa e Transparência Passiva. Isso significa que o aumento de 1 ponto na renda per capita do município eleva, em média, 0,0031 ponto o nível de Transparência Geral, 0,0033 ponto o nível de Transparência Ativa e Transparência Passiva. Com o aumento da renda municipal, a população exige melhor serviço público e mais informações para confirmar a boa aplicação dos recursos públicos. Essa atitude influencia as opiniões dos cidadãos sobre os impactos das políticas públicas, demonstrando, portanto, um sinal de qualidade de gestão, beneficiando os políticos locais ao aumentar suas chances de reeleição, assim como reduz os custos de agência (Alcaide Muñoz et al., 2016; Gandía \& Archidona, 2008).

O nível de desenvolvimento educacional exerce um impacto positivo no nível de Transparência Geral e Transparência Ativa. O efeito percebido sobre a transparência é alto, uma vez que, quando existe acréscimo de 1 ponto no Índice FIRJAN de Desenvolvimento Municipal em Educação, observa-se um acréscimo, em média, de 2,5635 pontos na Transparência Geral e de 4,0493 pontos na Transparência Ativa.

Uma população bem-educada deve exigir mais informações das administrações públicas (Tolbert, Mossberger, \& McNeal, 2008). Os cidadãos devem ter nível de educação suficiente para adquirir os conhecimentos e as habilidades necessários para fazer uso dos mecanismos da transparência pública e, portanto, saber examinar a informação disponível (Ríos et al., 2013).

A região exerce efeito positivo sobre os diferentes níveis de transparência. As regiões geográficas brasileiras agregam diferentes características socioeconômicas, por isso se mostram um determinante do nível de transparência.

Os investimentos de capital demonstraram um efeito positivo sobre o nível de Transparência Geral e Boas Práticas de Transparência. Esse resultado significa que cada acréscimo de 1 ponto no Indicador de Despesas de Capital representa um acréscimo, em média, de 3,9573 pontos no nível de Transparência Geral e de 4,1195 pontos no nível de Boas Práticas de Transparência. Os cidadãos brasileiros são interessados em relação ao desenvolvimento de projetos públicos que exigem um importante investimento, já que entendem que isso irá melhorar suas condições de vida. Desse modo, tal associação se justifica pelo fato de que os gestores públicos se envolvem em projetos de investimento significativos e utilizam a transparência para que os cidadãos possam visualizar esse tipo de informação não só em situações nas quais a informação é de divulgação obrigatória (Cárcaba García \& García García, 2010).

Por fim, também se observa um efeito positivo da competição política municipal sobre o nível de Transparência Geral. Esse resultado indica a condição de que cada aumento de 1 ponto no índice de competição política acarreta, em média, o aumento de 0,2658 pontos no nível de Transparência Geral dos municípios brasileiros. Isso representa o fato dos políticos, muitas vezes, ignorarem suas promessas pré-eleitorais após assumirem o cargo, uma vez que reconhecem a dificuldade dos cidadãos exercerem seu controle (Alcaide Muñoz et al., 2016; Cárcaba García \& García García, 2010). Entretanto, quando a fragmentação política é elevada, existindo forte oposição política, ela aumenta os custos dos 
políticos no descumprimento de suas promessas, o que obriga esses sujeitos a justificar e proporcionar transparência às suas ações (Alcaide Muñoz et al., 2016; Baber, 1983). Portanto, observa-se que a transparência reforça o mecanismo de controle pela sociedade e da própria oposição, o que melhora a qualidade da gestão pública.

\section{CONCLUSÃO}

Os resultados indicam que aspectos socioeconômicos são importantes determinantes da transparência pública dos municípios brasileiros. Os investimentos de capital e a competição política municipal também exercem um efeito positivo. Portanto, simplesmente não existe um efeito positivo dessas variáveis, mas a relação dessas variáveis com as diferentes perspectivas da transparência também tem um efeito diferente.

A transparência ativa capta a maior parte do interesse da sociedade, por isso, muitas vezes existe associação de aspectos socioeconômicos, financeiro-orçamentários e políticos sobre essa variável. A transparência passiva não parece ser facilmente explicada no modelo utilizado neste estudo. Uma explicação para tal é o fato de que são situações nas quais o ente municipal busca responder aos anseios da sociedade a partir de pedidos de informação, o que representa um processo mais demorado e difícil para o governo.

O número de habitantes representa a própria relação complexa entre a administração pública com a sociedade, o que faz com que os municípios sejam mais proativos quanto à transparência. Governos locais cuja população tenha maiores índices de renda per capita ou maiores níveis educacionais também têm um nível maior de transparência, pois buscam reconhecer onde seus tributos pagos ao governo são aplicados, o que é mais facilmente visível em uma população mais bem-educada e, portanto, participativa. As regiões geográficas brasileiras agregam diferentes características socioeconômicas e essas diferentes realidades influenciam os níveis de transparência.

A população acompanha projetos de investimentos de capital que são mais facilmente visíveis na gestão municipal, por isso, as situações em que um governo municipal investe mais nesse tipo de projeto justificam a associação positiva com a transparência, uma vez que os gestores públicos precisam antecipar-se e divulgar esse tipo de informação para a sociedade. A competição política aumenta o cuidado do gestor. Municípios cuja fragmentação política seja alta nas competições eleitorais exigem do gestor público uma postura mais transparente diante de seus adversários e da população, justamente para confirmar suas promessas pré-eleitorais.

A contribuição deste estudo é a identificação das principais variáveis determinantes do nível de transparência pública dos governos locais brasileiros, assim, diferencia-se dos demais pelo fato de observar os efeitos dos fatores financeiro-orçamentários e políticos nas diferentes dimensões da transparência. 


\section{REFERÊNCIAS}

Alcaide Muñoz, L., Rodríguez Bolívar, M. P., \& López Hernández, A. M. (2016). Transparency in governments: a meta-analytic review of incentives for digital versus hard-copy public financial disclosures. The American Review of Public Administration, 47(5), 550-573.

Alesina, A., \& Perotti, R. (1996). Income distribution, political instability, and investment. European Economic Review, 40(6), 1203-1228.

Alt, J. E., \& Lassen, D. D. (2006). Fiscal transparency, political parties, and debt in OECD countries. European Economic Review, 50(6), 1403-1439.

Alt, J. E., Mesquita, E. B., \& Rose, S. (2011). Disentangling accountability and competence in elections: evidence from US term limits. The Journal of Politics, 73(1), 171-186.

Baber, W. R. (1983). Toward understanding the role of auditing in the public sector. Journal of Accounting and Economics, 5, 213-227.

Bannister, F., \& Connolly, R. (2011). The trouble with transparency: a critical review of openness in e-government. Policy \& Internet, 3(1), 1-30.

Becker, G. S. (1968). Crime and punishment: an economic approach. In N. G. Fielding, A. Clarke, \& R. Witt (Eds.), The economic dimensions of crime (pp. 13-68). London, England: Palgrave Macmillan.

Besley, T., \& Case, A. (1995). Does electoral accountability affect economic policy choices? Evidence from gubernatorial term limits. The Quarterly Journal of Economics, 110(3), 769-798.

Buchanan, J. M., \& Tullock, G. (1962). The calculus of consent: logical foundations of constitutional democracy (Ann Arbor Paperbacks). Ann Arbor, MI: The University of Michigan Press.

Caamaño-Alegre, J., Lago-Peñas, S., Reyes-Santias, F., \& Santiago-Boubeta, A. (2013). Budget transparency in local governments: an empirical analysis. Local Government Studies, 39(2), 182-207.

Caba Pérez, M. C., Rodríguez Bolívar, M. P., \& López Hernández, A. M. (2008). E-government process and incentives for online public financial information. Online Information Review, 32(3), 379-400.
Caba Perez, M. C., Rodríguez Bolívar, M. P., \& López Hernández, A. M. (2014). The determinants of government financial reports online. Transylvanian Review of Administrative Sciences, 10(42), 5-31.

Calderón, C., \& Chong, A. (2006). Do democracies breed rent-seeking behavior? The Journal of Policy Reform, 9(4), 247-260.

Cárcaba García, A. I., \& García García, J. (2010). Determinants of online reporting of accounting information by Spanish local government authorities. Local Government Studies, 36(5), 679-695.

Cheng, R. H. (1992). An empirical analysis of theories on factors influencing state government accounting disclosure. Journal of Accounting and Public Policy, 11(1), 1-42.

Constituição da República Federativa do Brasil, de 5 de outubro de 1988. (1988). Brasília, DF.

Cross, H. L. (1953). The people's right to know; legal access to public records and proceedings. New York, NY: Columbia University Press.

Cucciniello, M., \& Nasi, G. (2014). Transparency for trust in government: how effective is formal transparency? International Journal of Public Administration, 37(13), 911-921.

Decreto n. 7.185, de 27 de maio de 2010. (2010). Dispõe sobre o padrão mínimo de qualidade do sistema integrado de administração financeira e controle, no âmbito de cada ente da Federação, nos termos do art. 48, parágrafo único, inciso III, da Lei Complementar n. 101, de 4 de maio de 2000, e dá outras providências.

Esteller-Moré, A., \& Otero, J. P. (2012). Fiscal transparency: (why) does your local government respond? Public Management Review, 14(8), 11531173.

Etzioni, A. (2010). Is transparency the best disinfectant? Journal of Political Philosophy, 18(4), 389-404.

Federação das Indústrias do Estado do Rio de Janeiro. (n.d.). Indice FIRJAN de Desenvolvimento Municipal (IFDM). Recuperado de www.firjan.com. br/ifdm

Fiirst, C., Costa, J. S., Baldissera, J. F., \& Dall'Asta, D. (2017). A influência de variáveis socioeconômicas e contábeis no índice de transparência eletrônica 
dos maiores municípios brasileiros, após a lei de acesso à informação. In Anais do 10o Congresso da Associação Nacional de Programas de Pós-Graduação em Contabilidade. Belo Horizonte, MG.

Gallego-Álvarez, I., Rodríguez-Domínguez, L., \& García-Sánchez, I.-M. (2010). Are determining factors of municipal e-government common to a worldwide municipal view? An intra-country comparison. Government Information Quarterly, 27(4), 423-430.

Gandía, J. L., \& Archidona, M. C. (2008). Determinants of web site information by Spanish city councils. Online Information Review, 32(1), 35-57.

García-Sánchez, I.-M., Frías-Aceituno, J.-V., \& Rodríguez-Domínguez, L. (2013). Determinants of corporate social disclosure in Spanish local governments. Journal of Cleaner Production, 39, 60-72.

Giroux, G. (1989). Political interests and governmental accounting disclosure. Journal of Accounting and Public Policy, 8(3), 199-217.

Giroux, G., \& Deis, D. (1993). Investor interests and government accounting disclosure. Accounting, Auditing \& Accountability Journal, 6(1), 63-78.

Grimmelikhuijsen, S. G., \& Welch, E. W. (2012). Developing and testing a theoretical framework for computer-mediated transparency of local governments. Public Administration Review, 72(4), 562-571.

Guillamón, M.-D., Bastida, F., \& Benito, B. (2011). The determinants of local government's financial transparency. Local Government Studies, 37(4), 391-406.

Guillamón, M.-D., Ríos, A.-M., Gesuele, B., \& Metallo, C. (2016). Factors influencing social media use in local governments: the case of Italy and Spain. Government Information Quarterly, 33(3), 460-471.

Hölmstrom, B. (1979). Moral hazard and observability. The Bell Journal of Economics, 10(1), 74-91.

Ingram, R. W. (1984). Economic incentives and the choice of state government accounting practices. Journal of Accounting Research, 22(1), 126-144.

Instituto Brasileiro de Geografia e Estatística. (2010). Censo 2010. Recuperado de www.censo2010.ibge. gov.br
Irvin, R. A., \& Stansbury, J. (2004). Citizen participation in decision making: is it worth the effort? Public Administration Review, 64(1), 55-65.

Klein, F. A., \& Sakurai, S. N. (2015). Term limits and political budget cycles at the local level: evidence from a young democracy. European Journal of Political Economy, 37, 21-36.

Lane, J.-E. (2006). Public administration \& public management: the principal-agent perspective. London, England: Routledge.

Laswad, F., Fisher, R., \& Oyelere, P. (2005). Determinants of voluntary internet financial reporting by local government authorities. Journal of Accounting and Public Policy, 24(2), 101-121.

Lei n. 12.527, de 18 de novembro de 2011. (2011). Regula o acesso a informações previsto no inciso XXXIII do art. $5^{\circ}$, no inciso II do $\$ 3^{\circ}$ do art. 37 e no $\$ 2^{\circ}$ do art. 216 da Constituição Federal; altera a Lei n. 8.112, de 11 de dezembro de 1990; revoga a Lei n. 11.111, de 5 de maio de 2005, e dispositivos da Lei n. 8.159, de 8 de janeiro de 1991; e dá outras providências. Brasília, DF.

Lei Complementar n. 101, de 4 de maio de 2000. (2000). Estabelece normas de finanças públicas voltadas para a responsabilidade na gestão fiscal e dá outras providências. Brasília, DF.

Meijer, A. (2009). Understanding modern transparency. International Review of Administrative Sciences, 75(2), 255-269.

Meijer, A. (2013). Understanding the complex dynamics of transparency. Public Administration Review, 73(3), 429-439.

Ministério Público Federal. (n.d.). Ranking Nacional de Transparência. Recuperado de http:// combateacorrupcao.mpf.mp.br/ranking

Mota, B. F., Diniz, J. A., \& Santos, L. C. (2017). A estrutura orçamentária como determinante do nível de transparência fiscal. Revista Contabilidade, Gestão e Governança, 20(2), 293-313.

Mueller, D. C. (1976). Public choice: a survey. Journal of Economic Literature, 14(2), 395-433.

Oliveira, C. B., \& Fontes, J. R., Filho. (2017). Problemas de agência no setor público: o papel dos intermediadores da relação entre poder central e unidades executoras. Revista de Administração Pública, 51(4), 596-615. 
RAP | Influência dos aspectos socioeconômicos, financeiro-orçamentários e político-eleitorais na transparência dos governos locais

Piotrowski, S. J., \& Van Ryzin, G. G. (2007). Citizen attitudes toward transparency in local government. The American Review of Public Administration, 37(3), 306-323.

Porumbescu, G. A. (2015). Using transparency to enhance responsiveness and trust in local government: can it work? State and Local Government Review, 47(3), 205-213.

Puron-Cid, G., \& Bolívar, M. P. R. (2018). The effects of contextual factors into different features of financial transparency at the municipal level. Government Information Quarterly, 35(1), 135-150.

Randolph, J., \& Bauer, M. (1999). Improving environmental decision-making through collaborative methods. Review of Policy Research, 16(3-4), 168-191.

Ríos, A.-M., Benito, B., \& Bastida, F. (2013). Determinants of central government budget disclosure: an international comparative analysis. Journal of Comparative Policy Analysis: Research and Practice, 15(3), 235-254.

Rodríguez Bolívar, M. P., Alcaide Muñoz, L., \& López Hernández, A. M. (2013). Determinants of financial transparency in government. International Public Management Journal, 16(4), 557-602.

Rogoff, K. (1990). Equilibrium political budget cycles. The American Economic Review, 80(1), 21-36.
Secretaria do Tesouro Nacional. (n.d.). Sistema de Informações Contábeis e Fiscais do Setor Público (Siconfi). Recuperado de www.siconfi.tesouro.gov.br

Serrano-Cinca, C., Rueda-Tomás, M., \& PortilloTarragona, P. (2009). Factors influencing e-disclosure in local public administrations. Environment and Planning C: Government and Policy, 27(2), 355-378.

Smith, K. A. (2004). Voluntarily reporting performance measures to the public: a test of accounting reports from US Cities. International Public Management Journal, 7(1), 19-48.

Sol, D. A. (2013). The institutional, economic and social determinants of local government transparency. Journal of Economic Policy Reform, 16(1), 90-107.

Supremo Tribunal Federal. (2015, 23 de abril). Recurso Extraordinário com Agravo 652.777 (Relator Min. Teori Zavascki). Brasília, DF.

Tolbert, C. J., Mossberger, K., \& McNeal, R. (2008). Institutions, policy innovation, and e-government in the American States. Public Administration Review, 68(3), 549-563.

Tribunal Superior Eleitoral. (n.d.). Recuperado de www.tse.jus.br

Zimmerman, J. L. (1977). The municipal accounting maze: an analysis of political incentives. Journal of Accounting Research, 15, 107-144. 


\section{Juliano Francisco Baldissera}

(1)

https://orcid.org/0000-0003-1592-5906

Mestre em Contabilidade pela Universidade Estadual do Oeste do Paraná (Unioeste); Professor assistente do Departamento de Ciências Contábeis da Universidade Estadual de Maringá (DCC/UEM).

E-mail: juliano.baldissera@hotmail.com

\section{Denis Dall'Asta}

https://orcid.org/0000-0002-2624-3364

Doutor em Engenharia de Produção pela Universidade Federal de Santa Catarina (UFSC); Professor do Programa de Pós-Graduação em Contabilidade da Universidade Estadual do Oeste do Paraná (Unioeste).

E-mail:denis.asta@unioeste.br

\section{Luiz Fernande Casagrande}

D

https://orcid.org/0000-0002-1117-0641

Doutor em Engenharia pela Universidade Federal do Rio Grande do Sul (UFRGS); Professor do curso de Graduação em Ciências Contábeis da Universidade Tecnológica Federal do Paraná (UTFPR).

E-mail: casagrande@utfpr.edu.br

\section{Abdinardo Moreira Barreto de Oliveira}

https://orcid.org/0000-0002-9377-6267

Doutor em Administração pela Universidade Federal de Pernambuco (UFPE); Professor do curso de Graduação em Administração e do Mestrado Profissional em Administração Pública em Rede Nacional (PROFIAP) da Universidade Tecnológica Federal do Paraná (UTFPR). E-mail: abdinardom@utfpr.edu.br 